\title{
Management and conservation of the kelp species Laminaria digitata: using genetic tools to explore the potential exporting role of the MPA "Parc naturel marin d'Iroise"
}

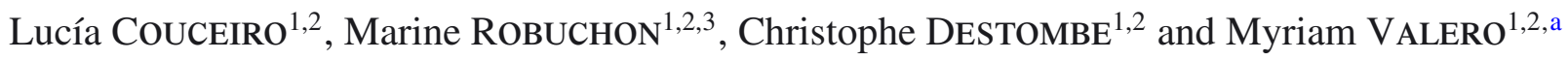 \\ 1 UPMC, UMR 7144, Adaptation et diversité en milieu marin, Équipe BEDIM, Station Biologique de Roscoff, Place Georges Teissier, \\ 29682 Roscoff, France \\ 2 CNRS, UMR 7144, Adaptation et diversité en milieu marin, Équipe BEDIM, Station Biologique de Roscoff, Place Georges Teissier, \\ 29682 Roscoff, France \\ 3 MNHN, UMR 7138, Systématique, adaptation, évolution, 57 rue Cuvier, 75231 Paris Cedex 05, France
}

Received 14 May 2012; Accepted 20 September 2012

\begin{abstract}
Marine protected areas (MPAs) have been depicted as a useful tool for improving fishery management and protecting biodiversity. For example, by acting as source populations, MPAs may provide a spillover of adults/propagules, enhancing recruitment to surrounding, non-protected waters. However, such positive effect will depend on how a MPAs design matches population biology and dispersal abilities of the target species. High levels of intraspecific genetic diversity without pronounced structure have been found in many marine organisms over large spatial scales (from hundreds to thousands kilometres) but do not hold for other ecologically and economically important species such as coral reef fishes, seagrasses and kelps. In particular, the limited potential for dispersal of many macroalgae suggests the occurrence of self-sustaining, "closed" populations that contrast with the "open" populations of many fishes and invertebrates. Consequently, the high resilience of fish/invertebrate populations cannot be generalized to the whole marine realm. In the present work, we use genetic tools to explore the role of the MPA Parc naturel marin d'Iroise in the management of the emblematic kelp Laminaria digitata. While kelps have received much more scientific attention than any other seaweed group, there is still critical baseline knowledge which needs to be addressed for their effective management. Our genetic survey of $12 \mathrm{~L}$. digitata populations along the Brittany coast, four of them located within the boundaries of the Parc naturel marin d'Iroise, allowed us to assess the conservation value of these kelp populations. In particular, classical genetic metrics as well as more recent clustering approaches were used to identify and characterize Management Units. Moreover, assignment tests were employed to determine contemporary migration events and source/sink populations. Our results show that populations within this MPA have high conservation value. However, we also identify other populations of conservation interest.
\end{abstract}

Keywords: Population genetic connectivity / Microsatellite markers / Gene flow / Gametophyte bank / Seaweed / Laminaria digitata / Marine protected area / Ushant front / Atlantic Ocean / Dispersal / Kelp / Marginal populations / Management units / Genetic diversity / Source/sink

\section{Introduction}

Marine Protected Areas (MPAs) cover many different types of protection. Some are "no-take zones" while others allow various levels of extractive activities (Kelleher 1999). Their main goal, as seen by the International Union for Conservation of Nature (IUCN), is to preserve biological diversity and to enhance the productivity of the oceans. Accordingly, a single MPA should be either self-sustaining or connected to other MPAs via dispersal (i.e. network of MPAs) to successfully accomplish its purpose and promote population persistence (Clinchy 1997). The effectiveness of a particular MPA

a Corresponding author: valero@sb-roscoff.fr will depend on its specific objectives, but MPAs are generally envisioned to play an ecosystem role on a scale larger than their own boundaries (Agardy 1994). For example, by acting as source populations (Pulliam 1988), MPAs have been shown to provide a spillover of adults/propagules, enhancing recruitment to surrounding, non-protected areas (Teske et al. 2010). Still, such positive effect will depend on how MPA designs match the population biology and dispersal abilities of target species. Connectivity is thus a critical parameter for optimizing the size and spacing of MPAs. However, getting direct measures of propagule dispersal in the sea has proven difficult (but see Almany et al. 2007) and genetic tools are frequently used as an alternative to infer connectivity and scales of population structure (Palumbi 2004). These 
methods have found widespread applications in the identification and conservation of populations and, in particular, they have helped to guide new approaches to fisheries management (Selkoe et al. 2008). The power of detecting migration through population genetic analyses has considerably improved during this last decade because of concomitant developments of DNA technologies, computational power and new sophisticated statistical methods (Waples et al. 2008). Among these new analytical tools, assignment methods (Paetkau et al. 2004; Manel et al. 2005) allow us to estimate the direction of migration between populations, thus providing important demographic information (e.g. source/sink dynamics) for sitting marine reserves (Crowder et al. 2000; Cowen and Sponaugle 2009).

Marine populations display a high spatio-temporal heterogeneity regarding genetic and demographic factors such as dispersal distances and settlement rates. The "open", nostructured populations of many exploited fishes (Carr et al. 2003; Kinlan et al. 2005) contrast with the "closed" populations of other ecologically and/or economically important species such as coral reef fishes (Jones et al. 2009), seagrasses (Procaccini et al. 2007) and kelps (Valero et al. 2011). Hence the high resilience of some exploited fish populations to human impacts due to a decoupling of local offspring production from propagule acquisition (Roughgarden et al. 1988) cannot be generalized to the entire marine world. Genetic data are therefore needed to characterize dispersal and population connectivity in these other ecologically and economically important marine resources.

The MPA Parc naturel marin d'Iroise (PNMI), located into the Ushant Sea (western Brittany, France), was created in October 2007 to promote a sustainable use of the regional marine resources including the kelp Laminaria digitata. In fact, $L$. digitata isone of the most commonly harvested species in Europe as a source of alginates. Indeed, more than $50 \%$ of the yield of $L$. digitata in France comes from the area of Molène located in the aforementioned MPA (Arzel 1998; Alban et al. 2011). Compared to other marine organisms, dispersal distances of spores and gametes are reported to be very limited in macroalgae (Santelices 1990), ranging from less than one metre to over $4 \mathrm{~km}$ (see Kinlan and Gaines 2003 and references therein). However, although rare, long-distance dispersal events might have essential consequences on population connectivity (Kinlan et al. 2005). In the particular case of kelps, dispersal is mainly ensured by planktonic haploid spores but long-distance dispersal may occur in some species via rafting individuals (Thiel and Gutow 2005). The few studies that have examined patterns of population connectivity of macroalgae also suggest that habitat discontinuity may be the main factor shaping spatial genetic differentiation (in L. digitata, Billot et al. 2003; Valero et al. 2011; in Durvinella antartica, Fraser et al. 2010; in Macrocystis pyrifera, Alberto et al. 2010; and in Hormosira banksii Coleman et al. 2011). Specifically, contrasting levels of genetic diversity have been reported in $L$. digitata between large continuous and small isolated populations along the Brittany coasts. Furthermore, the temporal genetic instability observed in these small populations (Valero et al. 2011) suggests that they are not self-sustaining units and their persistence might rely only on immigration from adjacent sources (sink populations).
In the present work, we use genetic tools to explore the potential exporting role of the PNMI in the conservation of the engineering kelp L. digitata. Our sampling scheme, ranging from Southern Brittany to the Gulf of Saint Malo, intended to compare populations within and outside the PNMI, but also populations differing in size (small isolated versus large continuous stands). Our main goal is to evaluate the conservation value of these populations based on three criteria inferred from genetic data: amount and distribution of the genetic diversity, level of resilience, and source/sink dynamics.

\section{Materials and methods}

\subsection{Sampling and genotyping}

In order to compare L. digitata populations within the $P N M I$ with surrounding populations, four localities sampled in 2006 into/nearby this MPA were added to a previous data set (Valero et al. 2011). To facilitate comparisons, the same population codes as those in Valero et al. (2011) were used here. The previously studied samples, collected during 2005/2006, involved eight populations placed either northwards (Northern Brittany: NB2, NB4, NB4, and Saint Malo Gulf: SM1) or southwards (Southern Brittany: SB3, SB2, and SB1) of the boundaries of the $P N M I$, as well as one population at its northern limit (NB1) (Fig. 1). The new data set included three populations located within the boundaries of the MPA PNMI (MPA1, MPA2, and MPA3)as well as one population placed $15 \mathrm{~km}$ southwards (SB4) (Fig. 1).

DNA extraction for the new samples was performed as in Valero et al. (2011). Likewise, the same seven microsatellite loci were amplified in these samples following previous protocols (Billot et al. 1998; Valero et al. 2011). In total, our dataset comprised 330 individuals (20-30 individuals per population) of which 115 were collected inside the aforementioned MPA.

\subsection{Summary statistics, Hardy-Weinberg expectations and linkage disequilibrium}

Standard measures of genetic diversity for each population were calculated in GENEALEX version 6.41 (Peakall and Smouse 2006): mean number of alleles per locus (Na), unbiased expected heterozygosity $(\mathrm{He})$, and number of private alleles. Moreover, all pairs of loci across sites were tested for linkage disequilibrium using a Markov chain approximation of an exact test as implemented in GENEPOP web version 4.0.10 (Raymond and Rousset 1995). Conformity to Hardy-Weinberg equilibrium within each sampling site was also assessed using the same software. In both cases, sequential Bonferroni correction was applied in order to account for multiple comparisons (Rice 1989).

\subsection{Population structure}

Genetic differentiation among populations was first investigated using pairwise $F_{\mathrm{ST}}$ estimates based on the approach 

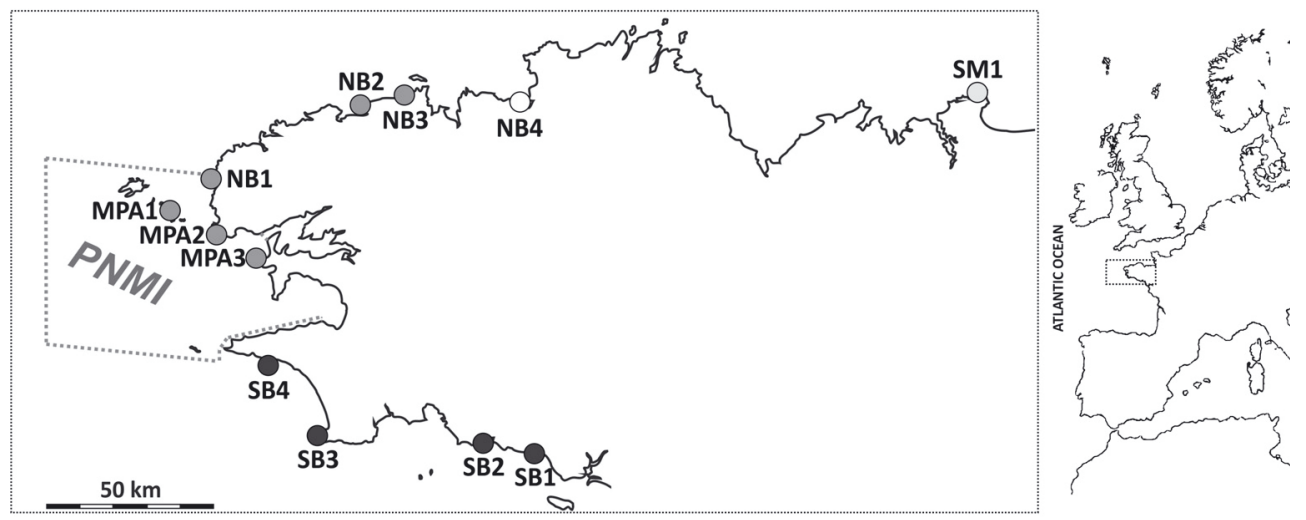

a)

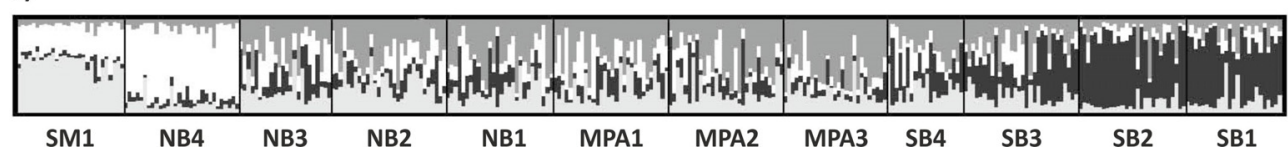

b)

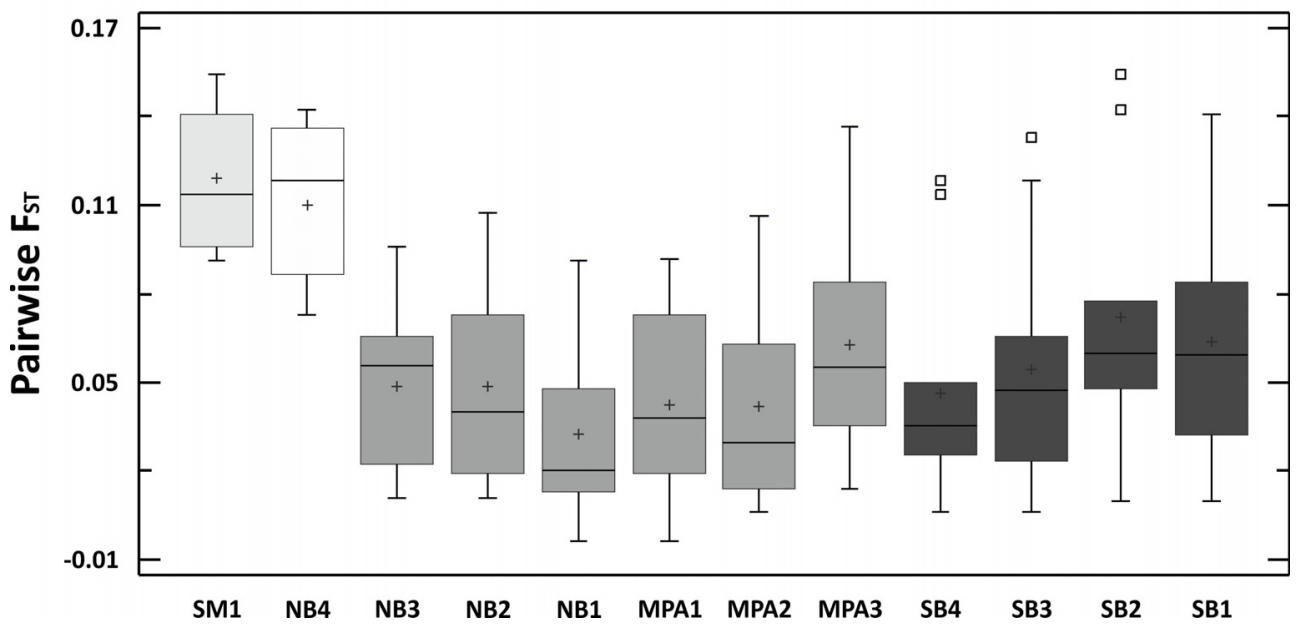

Fig. 1. Map of Brittany showing sampling sites and the perimeter of the Marine Protected Area Parc naturel marin d'Iroise (dotted line). (a) STRUCTURE bar plot for $K=4$ averaged over 20 independent runs; each vertical segment represents one single individual and colours indicate the relative contribution of each one of the 4 identified clusters to its genetic make-up. (b) Box-and-whisker plot of pairwise FST values for each population (colours indicate genetic clusters as identified by STRUCTURE).

of Weir and Cockerham (1984) and calculated in FSTAT version 2.93 (Goudet 1995). Deviation of obtained values from zero was tested by randomizing genotypes among samples (1320 permutations). For each of the N (12) studied populations, the N-1 (11) pairwise $\mathrm{F}_{\mathrm{ST}}$ values were averaged in order to get an estimate of their mean level of genetic differentiation.

In a separate analysis, the most likely number of genetic clusters was inferred using the STRUCTURE software, version 2.2 (Pritchard et al. 2000). This program was run under the admixture and independent allele frequency model using a Markov chain Monte Carlo length of 300000 steps after a burn-in of 200000 . The number of clusters $(K)$ was determined by estimating the probability of the data $[\ln \operatorname{Pr}(X \mid K)]$ for runs with $K=2-12$, averaged over 20 independent runs. The value of $K$ that most likely captured the major structure in the data was determined as the smallest $K$ at which average $\log \operatorname{Pr}(X \mid K)$ estimates levelled out. For the selected $K$, results from replicate runs were averaged with CLUMPP version 1.1.2 (Jakobsson and Rosenberg 2007) and displayed graphically using DISTRUCT version 1.1 (Rosenberg 2004). Moreover, the number and identity of the genetic clusters identified by this method was corroborated using the alternative bayesian approach implemented in BAPS version 5.2 (Corander et al. 2008).

\subsection{Contemporary migration and source/sink populations}

In order to estimate contemporary migration events among the studied populations, first-generation migrant tests were performed in GENECLASS2 (Piry et al. 2004). This approach computes for each individual the probability of belonging to the population where it was sampled (based on its multilocus 
Table 1. Genetic diversity estimates for the studied populations ( $N$ : sampling size, Na: mean number of alleles per locus $\pm \mathrm{SD}$, Nap: number of private alleles, He: unbiased expected heterozygosity; numbers in brackets denote mean values \pm SD re-estimated for $N=20$ ).

\begin{tabular}{llccc}
\hline Population & $\boldsymbol{N}$ & Na & Nap & He \\
\hline SM1 & 28 & $4.00 \pm 0.76[3.35 \pm 1.42]$ & $1[0.09 \pm 0.22]$ & $0.561 \pm 0.06$ \\
NB4 & 30 & $4.27 \pm 0.68[3.37 \pm 0.90]$ & $0[0.00 \pm 0.01]$ & $0.518 \pm 0.04$ \\
NB3 & 24 & $6.43 \pm 1.54[4.91 \pm 2.57]$ & $2[0.15 \pm 0.24]$ & $0.625 \pm 0.06$ \\
NB2 & 30 & $6.57 \pm 1.72[4.86 \pm 2.70]$ & $0[0.18 \pm 0.32]$ & $0.664 \pm 0.06$ \\
NB1 & 28 & $7.14 \pm 1.32[5.36 \pm 2.08]$ & $3[0.17 \pm 0.20]$ & $0.678 \pm 0.05$ \\
MPA1 & 30 & $7.14 \pm 1.22[5.40 \pm 2.12]$ & $2[0.24 \pm 0.33]$ & $0.700 \pm 0.04$ \\
MPA2 & 30 & $6.14 \pm 1.14[5.04 \pm 2.90]$ & $2[0.20 \pm 0.27]$ & $0.673 \pm 0.07$ \\
MPA3 & 27 & $6.71 \pm 1.80[4.81 \pm 2.02]$ & $0[0.04 \pm 0.09]$ & $0.665 \pm 0.06$ \\
SB4 & 20 & $5.86 \pm 0.99[4.52 \pm 1.78]$ & $1[0.27 \pm 0.23]$ & $0.610 \pm 0.07$ \\
SB3 & 30 & $6.86 \pm 1.32[4.68 \pm 2.17]$ & $1[0.14 \pm 0.20]$ & $0.578 \pm 0.08$ \\
SB2 & 28 & $5.29 \pm 1.09[3.95 \pm 1.72]$ & $0[0.02 \pm 0.04]$ & $0.545 \pm 0.09$ \\
SB1 & 25 & $5.29 \pm 1.23[4.08 \pm 2.32]$ & $0[0.05 \pm 0.09]$ & $0.523 \pm 0.11$ \\
\hline
\end{tabular}

genotype) and those individuals which fail to pass a given threshold $p$-value are considered first-generation migrants. Assignment probabilities were here calculated using the partially Bayesian method of Rannala and Mountain (1997) in combination with the Monte Carlo re-sampling algorithm of Paetkau et al. (2004). Moreover, since we did not sample all potential source sites, we used $L=L_{\text {home }}$ as the statistical criterion for the likelihood computation (critical $p$ fixed to 0.05 ).

Finally, the status of each populations as a source/sink was determined by characterizing its pattern of asymmetric migration (i.e. emigration minus immigration), a measure of the degree to which a population is a donor or a recipient of migrants. Emigration/immigration estimates were derived from GENECLASS2 output since, even though this program does not explicitly provide migration rates, a rough approximation can be obtained by dividing the number of individuals identified as migrants by the sample size (Manel et al. 2005).

\section{Results}

The seven microsatellite loci amplified from 5 (Ld158) to 22 ( $L d 371)$ alleles each. Levels of genetic diversity were highly variable among sampling sites (Table 1). The mean number of alleles per locus $(\mathrm{Na})$ ranged almost twofold across all localities, from 4.00 (SM1) to 7.14 (NB1 and MPA1). Unbiased expected heterozygosities (He) showed also a considerable range of values $(0.518-0.700)$ and, as for the previous estimate, lowest levels were found in those populations located at both edges of the sampling range $(0.518,0.523,0.545$, and 0.561 for NB4, SB1, SB2, and SM1, respectively). Finally, 12 of the 73 detected alleles (16.4\%) were unique to a given population (i.e. private alleles) with frequencies oscillating between 0.017 and 0.033 . In particular, the central population NB1 showed 3 private alleles while NB3, MPA1, and MPA2 showed 2, SM1, SB4 and SB3 exhibited only one, and none were found in NB4, NB2, MPA3, SB2, and SB1. In order to discard a potential bias in the observed pattern of genetic diversity due to unequal sampling sizes, allelic diversity estimates were recalculated using a rarefaction approach (Kalinowski 2005). Both allelic richness and private allelic richness corroborated previous results. Allelic richness values oscillated from 3.35 to
5.40 and depicted 3 main groups of populations: SM1, NB4, $\mathrm{SB} 2$, and SB1 with values between 3.35 and 4.08; NB3, NB2, MPA3, SB4, and SB3 with intermediate values (4.52-4.91); and NB1, MPA1, and MPA2 showing the highest estimates $(>5)$. Likewise, private allelic richness estimates were lower than 0.10 for SM1, NB4, MPA3, SB2, and SB1, but higher than 0.20 for the central populations MPA1 and SB4.

Tests for linkage disequilibrium revealed significant departures in 19 of 252 comparisons at a critical level of $p<0.05$. This amount of significant tests is slightly higher than the expected by chance as type I errors (i.e. 13). However, only 4 pairs of loci $(L d 124 / L d 148, L d 158 / L d 167, L d 167 / L d 371$ and Ld371/Ld704) showed consistent deviations in two or more localities, while departures in the remaining 10 involved just one population. Moreover, only one test remained significant after sequential Bonferroni correction reflecting that observed results are due to demographic phenomena within populations rather than physical linkage. Likewise, tests for HardyWeinberg equilibrium revealed significant departures in 10 of 84 comparisons at a critical level of $p<0.05$ but no population showed evidence of departure from random mating after Bonferroni correction.

Average values of $[\log \operatorname{Pr}(\mathrm{X} \mid \mathrm{K})]$ from STRUCTURE runs reached a plateau at $K=4$. Since a higher number of clusters did not change the geographical clustering pattern but increased considerably standard deviations, we chose $K=4$ as the number of genetic groups best capturing the structure of our data (Fig. 1a). Clustering using BAPS was consistent with this partition (results not shown) and, in both cases, results were highly coherent with the spatial arrangement of the sampled populations. Thus, while two of the identified clusters were each composed by a single, isolated population (SM1 and NB4), the remaining two brought together 6 and 4 adjacent sites (NB3, NB2, NB1, MPA1, MPA2, and MPA3 for one cluster -Northwestern Brittany- and SB4, SB3, SB2, and SB1 for the other -Southern Brittany-). On the other hand, levels of genetic admixture were highly variable among individuals covering almost the whole range of possible values (0.10-0.95). Nevertheless, despite this huge variability, substantial differences among clusters could be observed. Thus, individuals from NB4 cluster showed the lowest 
genetic admixture $(0.25 \pm 0.12)$ while individuals from SM1 and Southern Brittany clusters exhibited intermediate levels $(0.45 \pm 0.09$ and $0.48 \pm 0.27$, respectively) and individuals from Northwestern Brittany cluster presented the highest values $(0.60 \pm 0.20)$.

Results of genetic differentiation using average pairwise $F_{\text {ST }}$ statistics over each population were consistent with the above described pattern (Fig. 1b). Thus, estimates between the populations identified as two independent clusters by the bayesian approaches (i.e. marginal SM1 and NB4 populations) and all other populations were high and significant corroborating their relative genetic isolation. In particular, pairwise $F_{\mathrm{ST}}$ values for SM1 ranged from 0.09 to $0.15(0.12 \pm$ 0.02 ) while they oscillated between 0.07 and 0.14 for NB4 $(0.11 \pm 0.03)$. In contrast, $F_{\mathrm{ST}}$ estimates for those populations that characterize Northwestern Brittany cluster were on average half, ranging from 0.00 to $0.14(0.05 \pm 0.03)$. Finally, populations of Southern Brittany cluster showed $F_{\text {ST }}$ values slightly higher than those from Northwestern Brittany, even though they also showed substantial variability (from 0.01 to $0.15 ; 0.06 \pm 0.04)$. In fact, five comparisons in this last cluster (namely, SB4-SM1, SB4-NB4, SB3-SM1, SB2-SM1, and SB2-NB4) exhibited values numerically distant from the remaining 32 estimates, indicating increased genetic differentiation among the populations located at both edges of the sampling range.

First-generation migrant tests detected a total of 28 individuals $(9 \%)$ that could not be assigned to the population in which they were sampled based on the likelihood of their multilocus genotypes (Fig. 2a). As expected, a considerable proportion of these putative migrants occurred among populations belonging to the same genetic cluster (58\%, i.e. 15 individuals). In particular, $42 \%$ of these within-cluster migration events were observed into the Northwestern cluster while the remaining $15 \%$ occurred within the Southern cluster. Moreover, a substantial fraction of these within-cluster events involved adjacent populations ( $46 \%$ and $75 \%$ for the Northwestern cluster and the Southern cluster, respectively). Among-cluster migration was mainly due to exchanges between Northwestern and Southern clusters (82\%). The remaining putative migrants corresponded to 1 individual sampled in SB3 whose population of origin could not be identified and 3 individuals collected in NB4 but attributed to MPA1, SB3, and again, an unsampled population. Interestingly, the bridge between Northwestern and Southern populations was more frequently established by MPA2/SB4 but not MPA3/SB4. Also, in agreement with population structure results, it was noteworthy that no migration event was detected in SM1.

GENECLASS2 output also provided important insights about the directionality and asymmetry of gene flow. When all populations were taken into account, $58 \%$ of the migration events occurred northwards while $42 \%$ happened southwards. The same tendency could be observed within each cluster: $56 \%$ of the migrants from Northwestern populations moved northwards while this percentage was even higher for those migrants from Southern populations (63\%). However, the examination of gene flow directionality on a population basis also revealed some important exceptions to the previous pattern. For example, 4 of the 5 migrants from MPA2 moved southwards and the same behaviour was observed for 2 of the 3 migrants identified from NB2. The studied populations also showed a very different pattern regarding the asymmetry of their gene flow (Fig. 2b): while the net balance among emigration and immigration rates, was positive for 3 populations (MPA1, MPA2, and MPA3), it remained equal to zero in 4 populations (SM1, NB2, SB4, and SB3) or, was even negative in NB4, NB3, NB1, SB2, and SB1. In particular, the role of MPA1 as source population was prominent (7 emigrants versus 1 immigrant) whereas NB4 and NB1 showed the highest immigration rates.

\section{Discussion}

\subsection{Genetic architecture and connectivity of L. digitata populations along Brittany}

Large brown algae of the order Laminariales, also known as kelps, characterize intertidal and subtidal rocky shores of temperate regions (Bolton 2010). By forming a major biogenic habitat, these macroalgae sustain important associated biodiversity. However, they are also subject to growing anthropogenic pressures and a worldwide decline has been recently reported (Airoldi and Beck 2007). Ensuring that marine reserves adequately protect these habitats, including their connectivity, is therefore a key issue in conservation of temperate marine regions (Coleman et al. 2011).

In this study, we have characterized the pattern of genetic connectivity, including contemporary gene flow, of Brittany populations of $L$. digitata scattered within and around the MPA PNMI. Our results show that the studied populations, covering approximately $400 \mathrm{~km}$ of coastline, belong to 4 genetic groups. As expected, two of these groups were composed of a single population: the marginal populations SM1 and NB4. In agreement with the lack of available substrate, and therefore conspecific populations on the adjacent coastline (Billot et al. 2003; Valero et al. 2011), these two groups exhibited low genetic diversity and strong differentiation. Indeed, the influence of habitat discontinuity on population connectivity has been also evoked for other kelp species (Alberto et al. 2010; Fraser et al. 2010; Coleman et al. 2011). The two remaining groups revealed a clear differentiation between Northwestern and Southern Brittany. The Northwestern group brought together 6 adjacent populations, including the totality of the PNMI populations. Genetic diversity estimates achieved here their highest values and a substantial gene flow within-cluster but also between adjacent clusters was found. The Southern group was composed of the 4 populations located at the southern edge of our sampling range. Both genetic diversity and differentiation estimates showed a wider range of values, reflecting the higher heterogeneity of this cluster. Thus, although levels of genetic diversity were, on average, moderate, estimates for SB1 and SB2 were considerably low and comparable to those of SM1 and NB4; in contrast, SB3 and SB4 showed levels comparable to those of the neighbouring Northwestern cluster. Similarly, SB1 and SB2 exhibited genetic differentiation substantially higher than SB3 and SB4. Taken together, these results suggest the occurrence of a transition zone (SB3 and SB4) between Northwestern and Southern clusters. 
a)

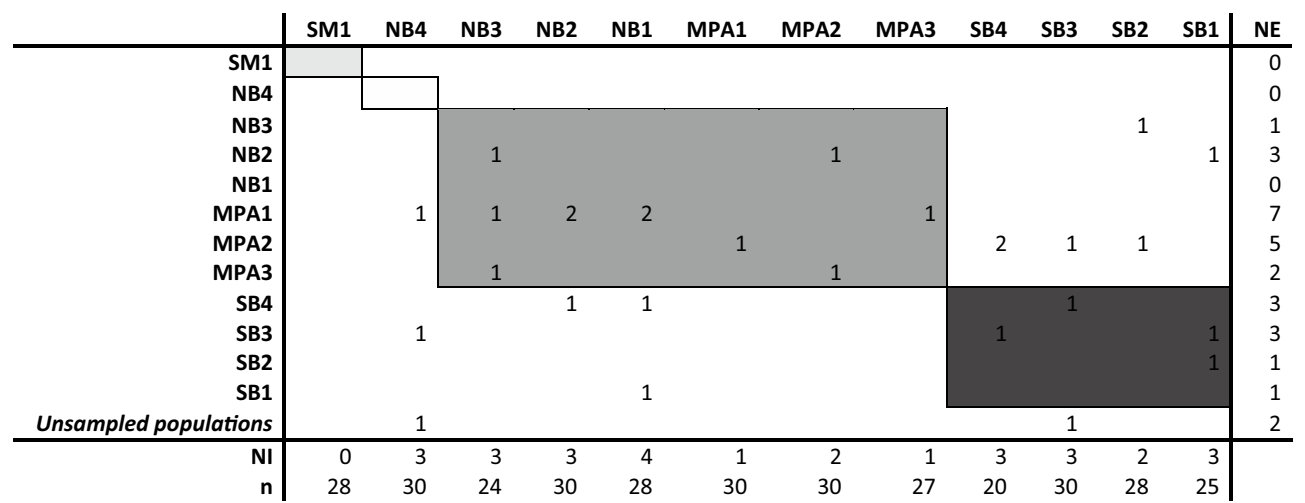

b)

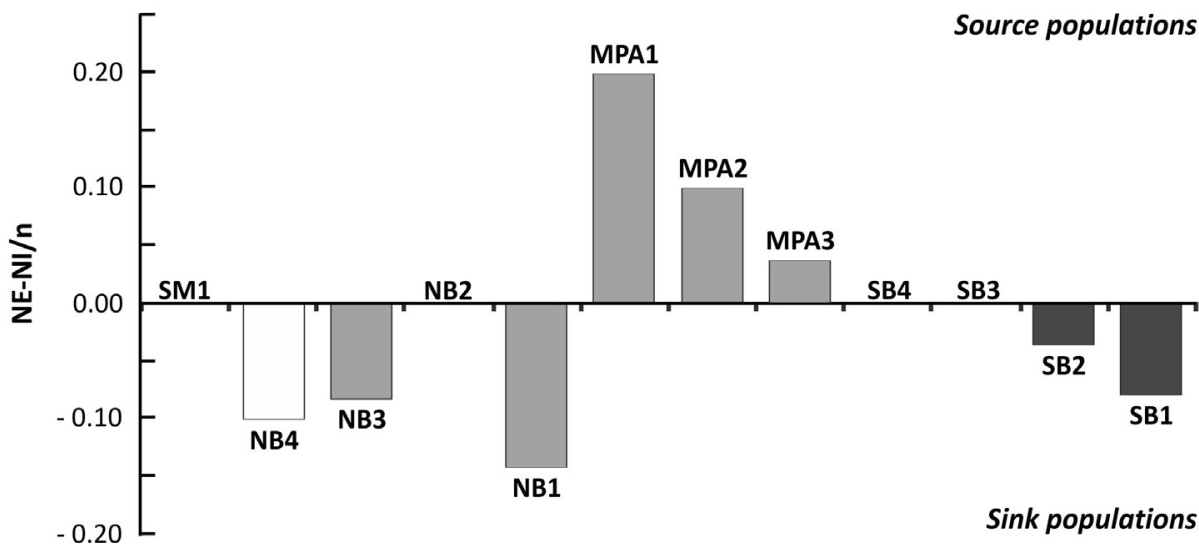

Fig. 2. (a) Results of first-generation migrant tests performed in GENECLASS2; columns assign to rows (NE: number of emigrants, NI: number of immigrants, $n$ : sample size). Colours denote the four genetic clusters identified by STRUCTURE. (b) Emigration-immigration asymmetry; positive values denote that a site is a net donor of migrants (source population) while negative values indicate a net recipient of migrants (sink population). Colours indicate STRUCTURE genetic clusters.

Interestingly, the genetic partition regarding the Northwestern and Southern clusters nearly fits the main hydrological features of the region (Ayata et al. 2010). In contrast with previous findings (Billot et al. 2003), this result suggests that connectivity among Southern and Northern Brittany populations is mainly determined by hydrodynamic features. The existence of an oceanic front joining Southern Brittany to Cornwall has been long described (Pingree 1975; Le Fèvre 1986). This thermal front, known as the Ushant front, appears in spring with the increase of ocean temperature and lasts until the mixing of the water column in autumn, thus preventing dispersal between the Bay of Biscay and the western English Channel. The clustering of our populations in two distinct, but not completely isolated groups fits well with this seasonal barrier. In fact, genetic isolation among populations at both edges of the Ushant front has been reported for other marine species (Jolly et al. 2005; Charrier et al. 2006). Besides, our results regarding contemporary gene flow also agree with the general north-northeastward drift of the North Atlantic Current (Koutsikopoulos and Le Cann 1996). However, even though migration mainly occurred northwards, we also find some exceptions illustrating that regional hydrodynamics are highly complex and include numerous mesoscale features (Ayata et al. 2010).
The division between Northwestern and Southern populations also agrees with the zonation of the marine biogeographical provinces in the Northeast Atlantic. The Iroise Sea is known to be a boundary between the Boreal and the Lusitanian provinces (Dinter 2001). Accordingly, the described genetic partition reflects that Northwestern populations clearly belong to the Boreal province while those from the Southern cluster are influenced by the adjacent Lusitanic province. Furthermore, our results regarding these two clusters also support the central-marginal hypothesis which predicts lower genetic diversity and higher differentiation for the populations at the limits of the species distribution range (Eckert et al. 2008). Like other cold-temperate species, L. digitata exhibits its southern limit of distribution in Europe around the 47th north parallel; hence Southern cluster populations are located at the south margin of its distribution range. As expected, genetic diversity was consistently higher in Northwestern than Southern populations whereas genetic differentiation suggested a lower connectivity in this last cluster. Indeed, fragmented populations as well as high ecological/demographical variability have been reported in other kelps near their limits of distribution (Coleman et al. 2011). These findings suggest that latitude is also an important factor structuring kelp populations; therefore, kelp genetic architecture might be as 
efficient as species distribution patterns for discriminating biogeographical provinces and defining habitats/areas of conservation concern.

\subsection{Implications for L. digitata management/ conservation}

Management units (MUs, i.e. functionally independent populations of conspecific individuals, Morizt 1994) have been recently proposed as a means to efficiently guide monitoring/conservation programs seeing that, populations within a given species may be sufficiently differentiated to require separate management (Frankham 2004). Even though MUs can rely on geography, demography or ecology, genetic data are increasingly being used to delineate them. Our analyses clearly demonstrate that all $L$. digitata populations within the PNMI belong to the same MU and should therefore be managed as a whole; this MU (here after referred as Northwestern MU) also includes two other populations located ca. $60 \mathrm{~km}$ beyond the PNMI northern limit. A second MU encompassing the four populations within the Southern cluster can be also defined (Southern MU). While it seems obvious that both MUs should be protected, the Northwestern MU exhibits certain features suggesting a higher conservation value. First, since Northwestern MU populations show the highest genetic diversity, they should harbour the largest genetic legacy of L. digitata within the region. Second, populations identified as sources by our analysis of asymmetric gene flow all belong to the Northwestern MU and, in particular, all are located inside the PNMI. Protecting source populations constitutes a widely-accepted guideline in MPA design (Roberts 1997). Since sources are self-sustaining populations but also produce a surplus of individuals (Jones et al. 2007), preserving them can increase recruitment/captures in the adjacent, non-protected populations (Roberts 1997). Finally, it has been argued that populations representing the best MPA candidates have to also exhibit high resilience so they can rescue other depleted populations (Salm et al. 2006). Although demographic data for the studied populations are not available, some insights suggest that Northwestern MU populations display high resilience. A spatio-temporal survey covering 7-9 years and comprising 8 of our 12 populations revealed no significant changes in genetic diversity/differentiation for Northwestern MU populations suggesting that effective population sizes have remained unchanged (Valero et al. 2011). In contrast, a significant change in the population genetic metrics was detected for the isolated populations SM1 and NB4 indicating that they have probably suffered a recent genetic impoverishment.

Even if Northwestern MU populations seem to fulfil the role of highly diverse, source, resilient populations, their protection alone might not ensure the long-term persistence of the species. Firstly, it is important to note that the PNMI is not a no-take MPA(even though some $L$. digitata stands around Sein Island have not been harvested for years and harvesting is strictly regulated; Le Niliot, pers. comm.). Indeed, it harbours some of the most exploited kelp populations in France. The management of these populations should therefore be considered with awareness to maintain their conservation potential.
Next, while protecting sources and/or highly-diverse populations is essential, sinks and/or less-diverse populations might also be of conservation concern. Although we have used neutral markers and we ignore whether Northwestern and Southern MUs are also divergent regarding adaptive traits, particular ecological/genetic conditions at the range edge might promote locally adaptive alleles (Bridle and Vines 2006). Finally, evidence indicates that southern Brittany populations of $L$. digitata show high interannual variability regarding population size: (i) theoretically, marginal populations are often small and subject to bottlenecks (Eckert et al. 2008); (ii) southern distribution of $L$. digitata might be constrained by overheating of North Atlantic waters (Arzel 1998); and (iii) field surveys carried out by the authors during the last decade also point to fluctuations in their demographic structure (unpublished data). However, it is important to remind that, while $L$. digitata displays a life-history alternating between two independent generations (a macroscopic diploid sporophyte and a microscopic haploid gametophyte), demographic data often focus on the macroscopic forms (but see Oppliger et al. 2012). Thus, populations might persist and self-sustain even when sporophytes have completely disappeared. The role of macroalgal microscopic stages as resistant forms has been actually largely debated. In a way analogous to terrestrial seed banks, Chapman (1986) coined the term "bank of microscopic forms" to designate the macroalgal microscopic stages able to survive environmental conditions too stressful for the macroscopic thalli thus allowing population persistence. The nature of such "bank of microscopic forms" has been quite investigated later but general conclusions are still lacking (reviewed in Hoffmann and Santelices 1991; Carney and Edwards 2006). Thus, while gametophytes can be affected by different environmental stresses (e.g. Dring et al. 1996), many studies advocate this stage as the resistant phase. In the particular case of kelps, two-week upper survival temperatures for Laminariales show that gametophytes exhibit higher tolerance than sporophytes in most species (Bartsch et al. 2008). Early investigations also demonstrate that Laminaria gametophytes can survive in a vegetative state in the absence of blue light and begin gametogenesis when it is present (Lüning 1981). Despite all above, there is no field evidence of delayed development in macroalgae excepting for the giant kelp Macrocystis pyrifera (Ladah and Zertuche-González 1999). Further field studies (or laboratory studies investigating interactive effects of multiple stressors) are therefore needed in order to make reliable ecological inferences.

\section{Conclusion}

In the present study, we illustrate the efficiency of molecular tools in identifying populations of conservation concern in the Brittany kelp L. digitata. While estimating connectivity is a key issue in conservation biology, obtaining direct measures of migration rates remains challenging in the marine realm, especially in species with microscopic dispersal phases. Using highly polymorphic microsatellites, patterns of both genetic diversity and structure were inferred using classical population genetic analysis. In addition, up-to-date clustering approaches and assignment tests were employed to identify MUs and 
sources/sink populations. Our study shows that PNMI populations belong to the same MU and actually exhibit high conservation value. The relevancein protecting other areas of the species range is also discussed.

Acknowledgements. Funding was provided by Agence Nationale de la Recherche (ECOKELP project, ANR06 BDIV 012). Additional supports from the Pôle Mer Bretagne, the Laboratoire International Associé "Dispersal and Adaptation of Marine Species" (LIA DIAMS) and the PNMI (convention CNRS-PNMI, LS 64816) are also acknowledged. L.C. and M.R. thank a postdoctoral fellowship from the Spanish Government (Secretaría de Estado de Universidades e Investigación, Ministerio de Educación) and a $\mathrm{PhD}$ fellowship from the French Government (Ministère de l'Enseigment Supérieur et de la Recherche) respectively.

\section{References}

Agardy M.T., 1994, Advances in marine conservation: the role of marine protected areas. Trends Ecol. Evol. 9, 267-270.

Airoldi L., Beck M.W., 2007, Loss, status and trends for coastal marine habitats of Europe. Oceanogr. Mar. Biol. Annu. Rev. 45, 345-405.

Alban F., Frangoudes K., Fresard M., 2011, Kelp harvesting fleet dynamics and the fleet's dependence on Laminaria forests in the Iroise Sea (North Finistere, France). Cah. Biol. Mar. 52, 507-516.

Alberto F., Raimondi P.T., Reed D.C., Coelho N.C., Leblois R., Whitmer A., Serrao E.A., 2010, Habitat continuity and geographic distance predict population genetic differentiation in giant kelp. Ecology 91, 49-56.

Almany G.R., Berumen M.L., Thorrold S.R., Planes S., Jones G.P, 2007, Local replenishment of coral reef fish populations in a marine reserve. Science 316, 742-744.

Arzel P., 1998, Les laminaires sur les côtes bretonnes. Evolution de l'exploitation et de la flottille de pêche, état actuel et perspectives. Ifremer edn.

Ayata S.D., Lazure P., Thiébaut E., 2010, How does the connectivity between populations mediate range limits of marine invertebrates? A case study of larval dispersal between the Bay of Biscay and the English Channel (North-East Atlantic). Prog. Oceanogr. $87,18-36$.

Bartsch I., Wiencke C., Bischof K., Buchholz C.M., Buck B.H., Eggert A., Feuerpfeil P., Hanelt D., Jacobsen S., Karez R., 2008, The genus Laminaria sensu lato: recent insights and developments. Eur. J. Phycol. 43, 1-86.

Billot C., Engel C.R., Rousvoal S., Kloareg B., Valero M., 2003, Current patterns, habitat discontinuities and population genetic structure: the case of the kelp Laminaria digitata in the English Channel. Mar. Ecol. Prog. Ser. 253, 111-121.

Billot C., Rousvoal S., Estoup A., Epplen J.T., Saumitou Laprade P., Valero M., Kloareg B., 1998, Isolation and characterization of microsatellite markers in the nuclear genome of the brown alga Laminaria digitata (Phaeophyceae). Mol. Ecol. 7, 1778-1780.

Bolton J.J., 2010, The biogeography of kelps (Laminariales, Phaeophyceae): a global analysis with new insights from recent advances in molecular phylogenetics. Helgol. Mar. Res. 64, 263-279.

Bridle J.R., Vines T.H, 2006, Limits to evolution at range margins: when and why does adaptation fail? Trends Ecol. Evol. 22, 140-147.
Carney L.T., Edwards M.S., 2006, Cryptic processes in the sea: a review of delayed development in the microscopic life stages of marine macroalgae. Algae 21, 161-168.

Carr M.H., Neigel J.E., Estes J.A., Andelman S., Warner R.R., Largier J.L., 2003, Comparing marine and terrestrial ecosystems: implications for the design of coastal marine reserves. Ecol. Appl. 13, S90-S107.

Chapman A.R.O., 1986, Population and community ecology of seaweeds. In: Blaxter J.H.S., Southwood A.J. (Eds.) Advances in marine biology, London, Academic Press, pp. 1-16.

Charrier G., Durand J.D., Quiniou L., Laroche J., 2006, An investigation of the population genetic structure of pollack (Pollachius pollachius) based on microsatellite markers. ICES J. Mar. Sci. 63, 1705-1709.

Clinchy M., 1997, Does immigration "rescue" populations from extinction? Implications regarding movement corridors and the conservation of mammals. Oikos 80, 618-622.

Coleman M.A., Chambers J., Knott N.A., Malcolm H.A., Harasti D., Jordan A., Kelaher B.P., 2011, Connectivity within and among a network of temperate marine reserves. PLoS ONE 6, e20168.

Corander J., Marttinen P., Sirén J., Tang J., 2008, Enhanced Bayesian modelling in BAPS software for learning genetic structures of populations. BMC Bioinf. 9, e539.

Cowen R.K., Sponaugle S., 2009, Larval dispersal and marine population connectivity. Annu. Rev. Mar. Sci. 1, 443-466.

Crowder L.B., Lyman S.J., Figueira W.F., Priddy J., 2000, Sourcesink population dynamics and the problem of siting marine reserves. Bull. Mar. Sci. 66, 799-820.

Dinter W., 2001, Biogeography of the OSPAR Maritime Area:a synopsis and synthesis of biogeographical distribution patterns described for the North-East Atlantic. Bonn, German Federal Agency for Nature Conservation.

Dring M.J., Makarov V., Schoschina E., Lorenz M., Lüning K., 1996, Influence of ultraviolet-radiation on chlorophyll fluorescence and growth in different life-history stages of three species of Laminaria (Phaeophyta). Mar. Biol. 126, 183-191.

Eckert C.G., Samis K.E., Lougheed S.C., 2008, Genetic variation across species' geographical ranges: the central-marginal hypothesis and beyond. Mol. Ecol. 17, 1170-1188.

Frankham R., Ballou J.D., Briscoe D.A., 2004, A primer of conservation genetics. New York, Cambridge University Press.

Fraser C.I., Thiel M., Spencer H.G, Waters J.M., 2010, Contemporary habitat discontinuity and historic glacial ice drive genetic divergence in Chilean kelp. BMC Evol. Biol. 10, e203.

Goudet J., 1995, FSTAT (Version 1.2): a computer program to calculate F-statistics. J. Hered. 86, 485-486.

Hoffmann A.J., Santelices B., 1991, Banks of algal microscopic forms: hypothesis on their functioning and comparisons with seed banks. Mar. Ecol. Prog. Ser. 79, 185-194.

Jakobsson M., Rosenberg N.A., 2007, CLUMPP: a cluster matching and permutation program for dealing with label switching and multimodality in analysis of population structure. Bioinformatics 23, 1801-1806.

Jolly M.T., Jollivet D., Gentil F., Thiébaut E., Viard F., 2005, Sharp genetic break between Atlantic and English Channel populations of the polychaete Pectinaria koreni, along the North coast of France. Heredity 94, 23-32.

Jones G.P., Srinivasan M., Almany G.R., 2007, Population connectivity and conservation of marine biodiversity. Oceanography 20, 100-111.

Jones G.P., Almany G.R., Russ G.R., Sale P.F., Steneck R.S., von Oppen M.J.H., Willis B.L., 2009, Larval retention and connectivity among populations of corals and reef fishes: history, advances and challenges. Coral Reefs 28, 307-325. 
Kalinowski S.T., 2005, HP-RARE 1.0: a computer program for performing rarefaction on measures of allelic richness. Mol. Ecol. Notes 5, 187-189.

Kelleher G., 1999, Guidelines for Marine Protected Areas. Gland and Cambridge, IUCN.

Kinlan B.P., Gaines S.D., 2003, Propagule dispersal in marine and terrestrial environments: a community perspective. Ecology 84, 2007-2020.

Kinlan B.P., Gaines S.D., Lester S.E., 2005, Propagule dispersal and the scales of marine community process. Divers. Distrib. 11, 139-148.

Koutsikopoulos C., Le Cann B., 1996, Physical processes and hydrological structures related to the Bay of Biscay anchovy. Sci. Mar. 60, 9-19.

Ladah L.B., Zertuche-González J.A., Hernández-Carmona G.,1999, Giant kelp (Macrocystis pyrifera, Phaeophyceae) recruitment near its southern limit in Baja California after mass disappearance during ENSO 1997-1998. J. Phycol. 35, 1106-1112.

Le Fèvre J., 1986, Aspects of the biology of frontal systems. Adv. Mar. Biol. 23, 163-299.

Lüning K., 1981, Egg release in gametophytes of Laminaria saccharina: induction by darkness and inhibition by blue light and UV. Br. Phycol. J. 16, 379-393.

Manel S., Gaggiotti O.E., Waples R.S., 2005, Assignment methods: matching biological questions with appropriate techniques. Trends Ecol. Evol. 20, 136-142.

Morizt C., 1994, Defining "Evolutionary Significant Units" for conservation. Trends Ecol. Evol. 9, 373-375.

Oppliger L.V., Correa J. A., Engelen A.H., Tellier F., Vieira V., Faugeron S., Valero M., Gomez G., Destombe C., 2012, Temperature effects on gametophyte life-history traits and geographic distribution of two cryptic kelp species. PLoS ONE 7, e39289.

Paetkau D., Slade R., Burden M., Estoup A., 2004, Genetic assignment methods for the direct, real-time estimation of migration rate: a simulation-based exploration of accuracy and power. Mol. Ecol. 13, 55-65.

Palumbi S.R., 2004, Marine reserves and ocean neighborhoods: the spatial scale of marine populations and their management. Annu. Rev. Environ. Resour. 29, 31-68.

Peakall R., Smouse P.E., 2006, GENALEX 6: genetic analysis in Excel. Population genetic software for teaching and research. Mol. Ecol. Notes 6, 288-295.

Pingree R., Pugh P., Holligan P., Forster G., 1975, Summer phytoplankton blooms and red tides along the tidal fronts in the approaches of the English Channel. Nature 258, 672-677.

Piry S., Alapetite A., Cornuet J.M., Paetkau D., Baudouin L., Estoup A., 2004, GENECLASS2: a software for genetic assignment and first-generation migrant detection. J. Hered. 95, 536-539.
Pritchard J.K., Stephens M., Donnelly P., 2000, Inference of population structure using multilocus genotype data. Genetics 155 , 945-959.

Procaccini G., Olsen J. L., Reusch T.B.H., 2007, Contribution of genetics and genomics to seagrass biology and conservation. J. Exp. Mar. Biol. Ecol. 350, 234-259.

Pulliam H.R., 1988, Sources, sinks, and population regulation. Am. Nat. 132, 652-661.

Rannala B., Mountain J.L., 1997, Detecting immigration by using multilocus genotypes. Proc. Natl. Acad. Sci. USA 94, 9197-9201.

Raymond M., Rousset F., 1995, GENEPOP (Version 1.2): population genetics software for exact tests and ecumenicism. J. Hered. 86, 248-249.

Rice W.R., 1989, Analyzing tables of statistical tests. Evolution 43, 223-225.

Roberts C.M., 1997, Connectivity and management of Caribbean coral reefs. Science 278, 1454-1457.

Rosenberg N.A., 2004, DISTRUCT: a program for the graphical display of population structure. Mol. Ecol. Notes 4, 137-138.

Roughgarden J., Gaines S., Possingham H., 1988, Recruitment dynamics in complex life cycles. Science 241, 1460-1466.

Salm R.V., Done T., McLeod E., 2006, Marine protected area planning in a changing climate. In: Phinney J.T., Hoegh-Guldberg O., Kleypas J., Skirving W., Strong A. (Eds.) Coral reefs and climate change: science and management, Washington, American Geophysical Union, pp. 207-221.

Santelices B., 1990, Patterns of reproduction, dispersal and recruitment in seaweeds. Oceanogr. Mar. Biol. Annu. Rev. 28, 177-276.

Selkoe K.A., Henzler C.M., Gaines S.D., 2008, Seascape genetics and the spatial ecology of marine populations. Fish Fish. 9, 363-377.

Teske P.R., Forget F.R.G., Cowley P.D., Heyden S., Beheregaray L.B., 2010, Connectivity between marine reserves and exploited areas in the philopatric reef fish Chrysoblephus laticeps (Teleostei: Sparidae). Mar. Biol. 157, 2029-2042.

Thiel M., Gutow L., 2005, The ecology of rafting in the marine environment. II. The rafting organisms and community. Oceanogr. Mar. Biol. Annu. Rev. 43, 279-418.

Valero M., Destombe C., Mauger S., Ribout C., Engel C.R., DaguinThiebaut C., Tellier F., 2011, Using genetic tools for sustainable management of kelps: a literature review and the example of Laminaria digitata. Cah. Biol. Mar. 52, 467-483.

Waples R.S., Punt A.E., Cope J.M., 2008, Integrating genetic data into management of marine resources: how can we do it better? Fish Fish. 9, 423-449.

Weir B.S., Cockerham C.C., 1984, Estimating $F$-statistics for the analysis of population structure. Evolution 38, 1358-1370. 